\title{
New Perspectives for the Nutritional Value of Vitamin K in Human Health
}

Carla SB Viegas ${ }^{1,2}$ and Dina C Simes ${ }^{1,2^{*}}$

${ }^{1}$ Centre of Marine Sciences (CCMAR), University of Algarve, 8005-139 Faro, Portugal

${ }^{2}$ GenoGla Diagnostics, Centre of Marine Sciences (CCMAR), University of Algarve, Faro, Portugal

*Corresponding author: Simes DS, Centre of Marine Sciences (CCMAR), University of Algarve, Campus de Gambelas, 8005-139 Faro, Portugal, Tel: +351-289-800100; Fax: +351-289-800069; E-mail: dsimes@ualg.pt

Rec date: May 26, 2016; Acc date: June 27, 2016; Pub date: July 05, 2016

Copyright: ( 2016 Viegas CSB et al. This is an open-access article distributed under the terms of the Creative Commons Attribution License, which permits unrestricted use, distribution, and reproduction in any medium, provided the original author and source are credited.

\begin{abstract}
Vitamin $\mathrm{K}$ is an essential micronutrient in the post-translational modification of specific glutamic acid residues (Glu) into Y-carboxyglutamic acid residues (Gla) in target proteins known as vitamin K-dependent proteins (VKDPs). In healthy conditions of sufficient vitamin $\mathrm{K}$ status, a vitamin $\mathrm{K}$ recycling system maintains sufficient vitamin $\mathrm{K}$ levels for proper $\mathrm{Y}$-carboxylation of VKDPs, and vitamin $\mathrm{K}$ antagonists (VKAs) widely used as anticoagulants inhibit vitamin $\mathrm{K}$ recycling. Besides its well-known function in the maintenance of normal coagulation, vitamin $\mathrm{K}$ has been reported to have other diverse physiological functions with impact in human health. In extra-hepatic tissues vitamin $\mathrm{K}$ deficiency results in impairment of VKDPs $y$-carboxylation with important implications in bone and cardiovascular health. Although most of the vitamin $\mathrm{K}$ effects have been associated with regulation of mineralization in connective tissues through the action of matrix Gla protein (MGP) and osteocalcin (OC), the discovery of Gla-rich protein (GRP) opens new perspectives on the potential therapeutic range of vitamin $\mathrm{K}$.
\end{abstract}

Keywords: Vitamin K; $\gamma$-carboxyglutamic acid; Menaquinones; Phylloquinone

\section{Introduction}

Vitamin $\mathrm{K}$ is a lipid-soluble vitamin originally discovered by Dam as a necessary factor for normal haemostasis [1]. For many years considered as required only for the synthesis of blood clotting factors in the liver, the continuous discovery of extra-hepatic Gla proteins clearly showed that vitamin $\mathrm{K}$ functions lies beyond its function in blood coagulation, and is involved in multiple biological processes such as in bone and in the vasculature [2-7]. Vitamin $\mathrm{K}$ is an essential micronutrient acting as cofactor for the post-translational modification of vitamin K-dependent proteins (VKDPs), where specific glutamic acid (Glu) residues can be modified to calcium binding $\gamma$ carboxyglutamic acid (Gla) residues, through the action of $\gamma$-glutamyl carboxylase (GGCX) enzyme [6-8]. The use of vitamin $\mathrm{K}$ antagonists (VKAs) such as warfarin, known to influence the carboxylation of Glu residues of the coagulation factors in liver, has been shown to also impair the $\gamma$-carboxylation of extra-hepatic VKDPs, resulting in unwanted pathological side-effects in tissues such as bone and blood vessels [6,7,9-12]. Recently, additional functions of vitamin $K$, such as anti-inflammatory, transcriptional regulator of osteoblastic genes, and inhibition of tumor progression, have been proposed to be mediated by a direct vitamin K effect rather than through VKDPs action $[13,14]$. However, the function of VKDPs associated to these emerging functions of vitamin $\mathrm{K}$ has been poorly explored. Vitamin $\mathrm{K}$ status has been inversely correlated with circulating inflammatory markers and proposed to exert its anti-inflammatory function by suppressing nuclear factor $\kappa \mathrm{B}(\mathrm{NF}-\kappa \mathrm{B})$ signal transduction [15-17]. Furthermore it has been suggested to have a protective effect against oxidative stress through blocking of reactive oxygen species generation [18].

\section{Vitamin K forms and recycling}

Naturally occurring vitamin $\mathrm{K}$ compounds with classical cofactor activity required for $\gamma$-carboxylation reaction, comprise the phylloquinone (vitamin K1), and a series of menaquinones (MKs) (vitamin K2), which share a common 2-methyl-1,4-naphthoquinone ring structure (also known as menadione (MD) or vitamin K3) and an isoprenoid side chain, that differs in length and degree of saturation, depending on the organism by which they are synthetized $[18,19]$. Phylloquinone contains a phytyl side chain, which has only one unsaturated bond, and is found in plants and cyanobacteria $[18,19]$. Menaquinones are predominantly produced by bacteria and composed by a side chain with repeating isoprene residues, each containing an unsaturated bond [18-20]. In human diet their main sources are fermented foods represented by cheese and curd in Western diets, and the traditional Japanese food made from soybeans, natto. Depending on the number of prenyl repeats, menaquinones are subcategorized as MK-n, with $\mathrm{n}$ corresponding to the number of isoprenoid units, generally ranging from 4 to 13 [18-20]. MK-4 and MK-7 are commonly used as vitamin $\mathrm{K} 2$ supplements. These molecular forms of vitamin $\mathrm{K}$ have different cofactor activities and behave differently in processes such as absorption, transport, cellular uptake, tissue distribution and turnover $[18,19]$. While $\mathrm{K} 1$ is a major type (>90\%) of dietary vitamin $\mathrm{K}$, its concentrations in animal tissues is remarkably low compared with those of menaquinones, especially MK-4, which is the major form $(>90 \%)$ of vitamin $\mathrm{K}$ in tissues. It is known that mammals have the ability to convert dietary $\mathrm{K} 1$ into MK-4, which is then stored in specific tissues [21]. This conversion was recently shown to be via side chain removal/addition mechanism with MD as the intermediate molecule, and specifically regulated at tissue level [21].

The $\gamma$-carboxylation of VKDPs, that comprises the conversion of Glu to Gla residues catalysed by the GGCX enzyme, requires the presence of a reduced form of vitamin $\mathrm{K}$ (vitamin $\mathrm{K}$ hydroquinone, $\mathrm{KH} 2$ ), carbon dioxide and oxygen, and the continuous recycling of vitamin $\mathrm{K}$ 2,3-epoxide $(\mathrm{KO})$ to its quinone $(\mathrm{K})$ and hydroquinone 
(KH2) forms, in successive reactions catalysed by vitamin $\mathrm{K}$ reductases $[8,22,23]$. The two enzymes known to be involved in this vitamin $\mathrm{K}$ cycle are vitamin $\mathrm{K}$ epoxide reductase (VKOR) and vitamin $\mathrm{K}$ reductase (VKR), in a process known as the vitamin $\mathrm{K}$ cycle $[8,22]$. Each vitamin $\mathrm{K}$ molecule can thus be recycled several thousand times with this vitamin $\mathrm{K}$ cycle, which is the reason why minute vitamin $\mathrm{K}$ amounts are sufficient to cover its daily diet requirements [24]. However, the present dietary reference values for vitamin $\mathrm{K}(90 \mu \mathrm{g} /$ day for women and $120 \mu \mathrm{g} /$ day for men) [10] are based on proper functioning of the blood coagulation factors to maintain normal haemostasis, and not on the $\gamma$-carboxylation status of other VKDPs such as matrix Gla protein (MGP), Gla-rich protein (GRP), and osteocalcin (OC), known to be of vital importance in bone and/or vascular health $[2-7,18,24]$. Interestingly, extra-hepatic Gla proteins have been shown to be present as incompletely $\gamma$-carboxylated forms in the majority of healthy adults $[4,25]$, and thus the biological activity of these proteins could be considered sub-optimal. Since VKOR is a dithiol dependent enzyme known to be inhibited by 4hydroxycoumarin anticoagulant drugs, such as warfarin, acenocoumarol, and phenprocoumon, the widely use of these oral anticoagulants acting as vitamin $\mathrm{K}$ antagonists (VKAs), has also been linked to unwanted side effects in several extra-hepatic tissues with adverse clinical outcomes $[4,7-9,11,12]$. Remarkably, despite the long use of VKA the exact mechanism of inhibition of VKOR remains to be elucidated [26].

\section{Vitamin K-antagonists as indicators of vitamin K importance in health}

The extra hepatic effects of VKAs were first suggested when it was found that women receiving VKAs treatment between the 6 th and $12^{\text {th }}$ week of pregnancy gave birth to children with severe bone abnormalities [27]. Since then, many in vitro and in vivo experiments have shown that VKAs induce vitamin $\mathrm{K}$ deficiency, which has been unequivocally related to increased mineralization of several tissues, particularly in the vascular tree and skeletal elements. Rats treated with warfarin presented extensive vascular calcification which could be inhibited by simultaneous treatments with vitamin $\mathrm{K}$ [28-30]. Furthermore, vitamin $\mathrm{K}$ was shown to induce a regression of preformed warfarin-induced vascular calcifications, with restoration of arterial distensibility [31]. The ApoE knockout mice model of atherosclerosis treated with warfarin displayed increased atherosclerotic plaque calcification and plaque vulnerability [32]. In humans, VKA use was associated with coronary artery plaque calcification in patients with suspected coronary artery disease (CAD), where calcification of coronary plaques significantly increased with prolonged VKA use [32,33]. Also, increased calcification of aortic valves was observed in patients receiving preoperative VKAs relative to non-treated patients $[34,35]$. Chronic kidney disease (CKD) patients, a population with a high prevalence of cardiovascular mortality and vascular calcifications, have been associated with subclinical vitamin $K$ deficiency [35,36]. In a CKD rat model, warfarin treatments increased vascular calcification while high dietary vitamin $\mathrm{K} 1$ increased vitamin $\mathrm{K}$ tissue concentrations and attenuated vascular calcification [37]. Calciphylaxis is an often fatal complication of end-stage renal disease characterized by subcutaneous small arterioles calcification. Interestingly, approximately $50 \%$ of stage 5 CKD patients who develop calciphylaxis were on VKA therapy, which was proposed as one of the risk factors in the absence of severe disorders of calcium metabolism $[9,38]$. In the population-based Rotterdam study vitamin K2 intake was found inversely related to all-cause mortality and severe aortic calcification [39]. Vitamin K supplementation has been demonstrated as able to reduce bone turnover and improving bone strength $[40,41]$, and higher levels of vitamin $\mathrm{K}$ intake were associated with decreased risk of hip fracture [42-44]. Higher doses of vitamin K2 have been administered for osteoporosis treatment in Japan for several years [45]. Decreased bone mineralization and turnover was reported in rats treated with warfarin [46], and long-term warfarin therapy in humans has been associated with decreased bone mineral density $[47,48]$. Subclinical vitamin $\mathrm{K}$ levels have also been associated with an increased risk of osteoarthritis development [49,50].

\section{Vitamin K mechanism of action}

It is presently accepted that the most plausible mechanism underlying dysregulated mineralization in soft tissues associated to vitamin $K$ is the impairment of $\gamma$-carboxylation in VKDPs that have been known to have a role as regulators of mineralization. Insufficient $\gamma$-carboxylation either by dietary vitamin $\mathrm{K}$ deficiency or impairment of vitamin $\mathrm{K}$ recycling leading to the exhaustion of vitamin $\mathrm{K}$ storage, results in the production of inactive undercarboxylated VKDP forms. OC and MGP have been widely associated with mineralized tissues, regulation of mineralization processes, and vascular ectopic calcification, and considered the two VKD target proteins involved in bone and vascular tissues health, respectively [2-7,9,51]. The accumulation of their undercarboxylated (uc) protein forms has been implicated with loss of functionality and pathological mineralization. OC is a small secreted protein with $46-50$ amino acids containing $3 \mathrm{Gla}$ residues in most species, and highly expressed and accumulated in bone [52]. Initial in vitro studies have shown that OC binds to hydroxyapatite (HA) through its Gla residues inhibiting HA formation [53]. OC knockout mice evidenced that $\mathrm{OC}$ acts as a negative regulator of bone formation without altering bone resorption or mineralization, with a role in stimulating bone mineral maturation [54,55]. OC is presently considered a marker for bone formation [56] and circulating uncarboxylated OC has been proposed as a sensitive marker for vitamin K deficiency [57,58]. MGP contains 4-5 Gla residues and is synthetized by chondrocytes, vascular smooth muscle cells (VSMCs), endothelial cells, and fibroblasts [51]. It is presently considered one of the most powerful vascular calcification inhibitor known to date, and it is undercarboxylated form has been proposed as a biomarker for cardiovascular calcification and for vitamin $\mathrm{K}$ status [51,59-61]. Knockout mice for MGP die within 8 weeks of birth due to massive vascular mineralization of the main arteries, a phenotype similar to that obtain with warfarin treatments [62]. Interestingly, the Keutel syndrome in humans, which is characterized by loss-of-function mutations in the MGP gene results in non-lethal abnormal soft tissues calcification, which suggest additional or compensatory mechanisms of mineralization inhibition in humans. The discovery of an additional VKDP, Gla-rich protein (GRP), also expressed and accumulated in skeletal and vascular tissues [63-65], that we have recently shown to function as a calcification inhibitor in the cardiovascular [66] and articular systems [67], should open a new window of knowledge in the area of pathological calcification of connective tissues and increase the range of vitamin $\mathrm{K}$ action. GRP was initially identified in sturgeon calcified cartilage and characterized by the presence of an unprecedented 16 Gla residues within its 74 amino acid total protein sequence, and an impressive degree of evolutionary conservation [63]. The metal binding properties of Gla residues within the VKDP family have been associated with binding of calcium ions or calcium crystals, either through $\mathrm{Ca}^{2+}$ coordination in the $\mathrm{Ca}^{2+-}$ dependent binding of coagulation factors to anionic phospholipids membrane surfaces [68], 
or through binding to HA crystals, the major mineral component present in mineralized extracellular matrix, and associated either with physiological (eg., in bone) or pathological processes in soft tissues [69]. Fully $\gamma$-carboxylated GRP in human can include 15 Gla residues, which confers to this protein outstanding calcium and mineral binding capacity $[25,63,64]$. Undercarboxylation of GRP has been recently associated with several pathological calcification related diseases, as calcific aortic valve disease [66], osteoarthritis [67] and certain cancers [25], while only $\gamma$-carboxylated GRP has shown to display antimineralization capacity [66,67]. Interestingly, we have recently shown that GRP is involved in the crosstalk between inflammation and calcification of articular tissues in osteoarthritis, acting as an antiinflammatory agent [67]. Since calcification and inflammation are common and interconnected events in calcification-related chronic inflammatory diseases, the importance of GRP and vitamin $\mathrm{K}$ might acquire a new dimension in healthy and pathological states. Since the focus of VKAs treatments in ectopic calcification has been mainly restricted to the function of MGP and OC, the effects on GRP functionality and the consequences in the mineralization levels are currently unknown. However, it reinforces the notion that special care should be given to the widely used VKAs agents whose side effects are certainly still not completely unraveled.

\section{Conclusions}

Although innumerous studies have shown a protective role of vitamin $\mathrm{K}$ against pathological mineralization by improving the function of VKDPs acting as calcification regulators, and no toxicity is known for higher vitamin $\mathrm{K}$ dosages, the unequivocal beneficial effect on vitamin $\mathrm{K}$ supplementation in human dietary is still debatable. Nevertheless, vitamin $\mathrm{K}$ is a potential therapeutic target for highly prevalent diseases involving pathological mineralization such as cardiovascular diseases and osteoarthritis. In addition, the knowledge of the association of inflammatory processes to the etiology of these diseases and the increased attention to novel biological functions of vitamin $\mathrm{K}$, namely its antioxidant and anti-inflammatory role, should point for a more global evaluation of its role in human health and its beneficial use as a nutritional supplement. Furthermore, despite the detrimental side effects of VKAs therapy, additional studies on longterm vascular, bone and systemic effects of warfarin need to be performed, in order to understand whether its proven benefits in patients at risk of thromboembolic disease prevails over its negative impact in connective tissues. In this area there is a growing scientific knowledge underscoring a need for anticoagulants that do not interfere with the vitamin K-cycle.

\section{Acknowledgements}

This work was funded by projects PTDC/SAU-ORG/117266/2010 and PTDC/BIM-MEC/1168/2012, and also through project UID/ Multi/04326/2013, all from the Portuguese Science and Technology Foundation (FCT). CSB Viegas was the recipient of the FCT fellowship SFRH/BPD/70277/2010.

\section{References}

1. Dam H (1935) The antihaemorrhagic vitamin of the chick: occurrence and chemical nature. Nature 135: 652-653.

2. Cranenburg EC, Schurgers LJ, Vermeer C (2007) Vitamin K: the coagulation vitamin that became omnipotent. Thromb Haemost 98: 120-125.
3. Ferland G (2012) The discovery of vitamin $\mathrm{K}$ and its clinical applications. Ann Nutr Metab 61: 213-218.

4. Theuwissen E, Smit E, Vermeer C (2012) The role of vitamin K in softtissue calcification. Adv Nutr 3: 166-173.

5. Weber P (2001) Vitamin K and bone health. Nutrition 17: 880-887.

6. Kidd PM (2010) Vitamins D and $\mathrm{K}$ as pleiotropic nutrients: clinical importance to the skeletal and cardiovascular systems and preliminary evidence for synergy. Altern Med Rev 15: 199-222.

7. Willems BA, Vermeer C, Reutelingsperger CP, Schurgers LJ (2014) The realm of vitamin $\mathrm{K}$ dependent proteins: shifting from coagulation toward calcification. Mol Nutr Food Res 58: 1620-1635.

8. Tie JK, Stafford DW (2016) Structural and functional insights into enzymes of the vitamin K cycle. J Thromb Haemost 14: 236-247.

9. Chatrou ML, Winckers K, Hackeng TM, Reutelingsperger CP, Schurgers LJ (2012) Vascular calcification: the price to pay for anticoagulation therapy with vitamin K-antagonists. Blood Rev 26: 155-166.

10. DiNicolantonio JJ, Bhutani J, O'Keefe JH (2015) The health benefits of vitamin K. Open Heart 2: e000300.

11. Namba S, Yamaoka-Tojo M, Hashikata T, Ikeda Y, Kitasato L, et al. (2015) Long-term warfarin therapy and biomarkers for osteoporosis and atherosclerosis. BBA Clin 4: 76-80.

12. van Gorp RH, Schurgers LJ (2015) New Insights into the Pros and Cons of the Clinical Use of Vitamin K Antagonists (VKAs) Versus Direct Oral Anticoagulants (DOACs). Nutrients 7: 9538-9557.

13. Ohsaki Y, Shirakawa H, Miura A, Giriwono PE, Sato S, et al. (2010) Vitamin $\mathrm{K}$ suppresses the lipopolysaccharide-induced expression of inflammatory cytokines in cultured macrophage-like cells via the inhibition of the activation of nuclear factor $\mathrm{\kappa B}$ through the repression of IKK $\alpha / \beta$ phosphorylation. J Nutr Biochem 21: 1120-1126.

14. Fujii S, Shimizu A, Takeda N, Oguchi K, Katsurai T, et al. (2015) Systematic synthesis and anti-inflammatory activity of $\omega$-carboxylated menaquinone derivatives - Investigations on identified and putative vitamin K2 metabolites. Bioorg Med Chem 23: 2344-2352.

15. Shea MK, Booth SL, Massaro JM, Jacques PF, D'Agostino RB, et al. (2008) Vitamin $\mathrm{K}$ and vitamin D status: associations with inflammatory markers in the Framingham Offspring Study. Am J Epidemiol 167: 313-320.

16. Yamaguchi $M$, Weitzmann MN (2011) Vitamin K2 stimulates osteoblastogenesis and suppresses osteoclastogenesis by suppressing NF$\hat{I}^{\circ} \mathrm{B}$ activation. Int J Mol Med 27: 3-14.

17. Li J, Wang H, Rosenberg PA (2009) Vitamin $\mathrm{K}$ prevents oxidative cell death by inhibiting activation of 12-lipoxygenase in developing oligodendrocytes. J Neurosci Res 87: 1997-2005.

18. Shearer MJ, Newman P (2008) Metabolism and cell biology of vitamin K. Thromb Haemost 100: 530-547.

19. Shearer MJ, Newman P (2014) Recent trends in the metabolism and cell biology of vitamin $\mathrm{K}$ with special reference to vitamin $\mathrm{K}$ cycling and MK-4 biosynthesis. J Lipid Res 55: 345-362.

20. Walther B, Karl JP, Booth SL, Boyaval P (2013) Menaquinones, bacteria, and the food supply: the relevance of dairy and fermented food products to vitamin K requirements. Adv Nutr 4: 463-473.

21. Al Rajabi A, Booth SL, Peterson JW, Choi SW, Suttie JW, et al. (2012) Deuterium-labeled phylloquinone has tissue-specific conversion to menaquinone-4 among Fischer 344 male rats. J Nutr 142: 841-845.

22. Stafford DW (2005) The vitamin K cycle. J Thromb Haemost 3: 1873-1878.

23. Rishavy MA, Berkner KL (2012) Vitamin K oxygenation, glutamate carboxylation, and processivity: defining the three critical facets of catalysis by the vitamin K-dependent carboxylase. Adv Nutr 3: 135-148.

24. Shearer MJ, Fu X, Booth SL (2012) Vitamin K nutrition, metabolism, and requirements: current concepts and future research. Adv Nutr 3: 182-195.

25. Viegas CS, Herfs M, Rafael MS, Enriquez JL, Teixeira A, et al. (2014) Glarich protein is a potential new vitamin $\mathrm{K}$ target in cancer: evidences for a direct GRP-mineral interaction. Biomed Res Int 2014: 340216. 
26. Van Horn WD (2013) Structural and functional insights into human vitamin $\mathrm{K}$ epoxide reductase and vitamin $\mathrm{K}$ epoxide reductase-like1. Crit Rev Biochem Mol Biol 48: 357-372.

27. Pettifor JM, Benson R (1975) Congenital malformations associated with the administration of oral anticoagulants during pregnancy. J Pediatr 86: 459-462.

28. Price PA, Williamson MK, Haba T, Dell RB, Jee WS (1982) Excessive mineralization with growth plate closure in rats on chronic warfarin treatment. Proc Natl Acad Sci U S A 79: 7734-7738.

29. Price PA, Faus SA, Williamson MK (1998) Warfarin causes rapid calcification of the elastic lamellae in rat arteries and heart valves. Arterioscler Thromb Vasc Biol 18: 1400-1407.

30. Krüger T, Oelenberg S, Kaesler N, Schurgers LJ, van de Sandt AM, et al. (2013) Warfarin induces cardiovascular damage in mice. Arterioscler Thromb Vasc Biol 33: 2618-2624.

31. Schurgers LJ, Spronk HM, Soute BA, Schiffers PM, DeMey JG, et al. (2007) Regression of warfarin-induced medial elastocalcinosis by high intake of vitamin $\mathrm{K}$ in rats. Blood 109: 2823-2831.

32. Schurgers LJ, Joosen IA, Laufer EM, Chatrou ML, Herfs M, et al. (2012) Vitamin $\mathrm{K}$ antagonists accelerate atherosclerotic calcification and induce a vulnerable plaque phenotype. PLoS One 7: e43229.

33. Schurgers LJ, Aebert H, Vermeer C, Bültmann B, Janzen J (2004) Oral anticoagulant treatment: friend or foe in cardiovascular disease? Blood 104: 3231-3232.

34. Koos R, Mahnken AH, Mühlenbruch G, Brandenburg V, Pflueger B, et al. (2005) Relation of oral anticoagulation to cardiac valvular and coronary calcium assessed by multislice spiral computed tomography. Am J Cardiol 96: 747-749.

35. Holden RM, Morton AR, Garland JS, Pavlov A, Day AG, et al. (2010) Vitamins $\mathrm{K}$ and D status in stages 3-5 chronic kidney disease. Clin J Am Soc Nephrol 5: 590-597.

36. Cranenburg EC, Schurgers LJ, Uiterwijk HH, Beulens JW, Dalmeijer GW, et al. (2012) Vitamin $\mathrm{K}$ intake and status are low in hemodialysis patients. Kidney Int 82: 605-610.

37. McCabe KM, Booth SL, Fu X, Shobeiri N, Pang JJ, et al. (2013) Dietary vitamin $\mathrm{K}$ and therapeutic warfarin alter the susceptibility to vascular calcification in experimental chronic kidney disease. Kidney Int 83: 835-844.

38. Guzman UV, de la Cueva P, Verde E, de Vinuesa SG, Goicoechea M, et al (2008) Calciphylaxis: fatal complication of cardiometabolic syndrome in patients with end stage kidney disease. Nefrologia 28: 32-36.

39. Geleijnse JM, Vermeer C, Grobbee DE, Schurgers LJ, Knapen MH, et al. (2004) Dietary intake of menaquinone is associated with a reduced risk of coronary heart disease: the Rotterdam Study. J Nutr 134: 3100-3105.

40. Bügel S (2008) Vitamin K and bone health in adult humans. Vitam Horm 78: 393-416.

41. Price CT, Langford JR, Liporace FA (2012) Essential Nutrients for Bone Health and a Review of their Availability in the Average North American Diet. Open Orthop J 6: 143-149.

42. Feskanich D, Weber P, Willett WC, Rockett H, Booth SL, et al. (1999) Vitamin K intake and hip fractures in women: a prospective study. Am J Clin Nutr 69: 74-79.

43. Shiraki M, Shiraki Y, Aoki C, Miura M (2000) Vitamin K2 (menatetrenone) effectively prevents fractures and sustains lumbar bone mineral density in osteoporosis. J Bone Miner Res 15: 515-521.

44. Iwamoto J (2014) Vitamin K2, therapy for postmenopausal osteoporosis. Nutrients 6: 1971-1980.

45. Iwamoto J, Takeda T, Sato Y (2006) Menatetrenone (vitamin K2) and bone quality in the treatment of postmenopausal osteoporosis. Nutr Rev 64: 509-517.

46. Fusaro M, Carbonare DL, Dusso A, Arcidiacono MV, Valenti MT, et al. (2015) Differential Effects of Dabigatran and Warfarin on Bone Volume and Structure in Rats with Normal Renal Function. PLoS One 10: e0133847.
47. Rezaieyazdi Z, Falsoleiman H, Khajehdaluee M, Saghafi M, MokhtariAmirmajdi E (2009) Reduced bone density in patients on long-term warfarin. Int J Rheum Dis 12: 130-135.

48. Barnes C, Newall F, Ignjatovic V, Wong P, Cameron F, et al. (2005) Reduced bone density in children on long-term warfarin. Pediatr Res 57: 578-581.

49. Misra D, Booth SL, Tolstykh I, Felson DT, Nevitt MC, et al. (2013) Vitamin K deficiency is associated with incident knee osteoarthritis. Am J Med 126: 243-248.

50. Neogi T, Booth SL, Zhang YQ, Jacques PF, Terkeltaub R, et al. (2006) Low vitamin $\mathrm{K}$ status is associated with osteoarthritis in the hand and knee. Arthritis Rheum 54: 1255-1261.

51. Schurgers LJ, Uitto J, Reutelingsperger CP (2013) Vitamin K-dependent carboxylation of matrix Gla-protein: a crucial switch to control ectopic mineralization. Trends Mol Med 19: 217-226.

52. Price PA, Poser JW, Raman N (1976) Primary structure of the gammacarboxyglutamic acid-containing protein from bone. Proc Natl Acad Sci USA 73: 3374-3375.

53. Poser JW, Price PA (1979) A method for decarboxylation of gammacarboxyglutamic acid in proteins. Properties of the decarboxylated gamma-carboxyglutamic acid protein from calf bone. J Biol Chem 254: 431-436.

54. Ducy P, Desbois C, Boyce B, Pinero G, Story B, et al. (1996) Increased bone formation in osteocalcin-deficient mice. Nature 382: 448-452.

55. Boskey AL, Gadaleta S, Gundberg C, Doty SB, Ducy P, et al. (1998) Fourier transform infrared microspectroscopic analysis of bones of osteocalcin-deficient mice provides insight into the function of osteocalcin. Bone 23: 187-196.

56. Lumachi F, Ermani M, Camozzi V, Tombolan V, Luisetto G (2009) Changes of bone formation markers osteocalcin and bone-specific alkaline phosphatase in postmenopausal women with osteoporosis. Ann N Y Acad Sci 1: E60-E63.

57. Schoon EJ, Müller MC, Vermeer C, Schurgers LJ, Brummer RJ, et al. (2001) Low serum and bone vitamin $\mathrm{K}$ status in patients with longstanding Crohn's disease: another pathogenetic factor of osteoporosis in Crohn's disease? Gut 48: 473-477.

58. Gundberg CM, Lian JB, Booth SL (2012) Vitamin K-dependent carboxylation of osteocalcin: friend or foe? Adv Nutr 3: 149-157.

59. Schurgers LJ, Teunissen KJ, Knapen MH, Kwaijtaal M, van Diest R, et al. (2005) Novel conformation-specific antibodies against matrix gamma carboxyglutamic acid (Gla) protein:undercarboxylated matrix Gla protein as marker for vascular calcification. Arterioscler Thromb Vasc Biol 25: 1629-1633.

60. Cranenburg EC, Vermeer C, Koos R, Boumans ML, Hackeng TM, et al. (2008) The circulating inactive form of matrix Gla Protein (ucMGP) as a biomarker for cardiovascular calcification. J Vasc Res 45: 427-436.

61. Cranenburg EC, Koos R, Schurgers LJ, Magdeleyns EJ, Schoonbrood TH, et al. (2010) Characterisation and potential diagnostic value of circulating matrix Gla protein (MGP) species. Thromb Haemost 104: 811-822.

62. Luo G, Ducy P, McKee MD, Pinero GJ, Loyer E, et al. (1997) Spontaneous calcification of arteries and cartilage in mice lacking matrix GLA protein. Nature 386: 78-81.

63. Viegas CS, Simes DC, Laizé V, Williamson MK, Price PA, et al. (2008) Gla-rich protein (GRP), a new vitamin K-dependent protein identified from sturgeon cartilage and highly conserved in vertebrates. J Biol Chem 283: 36655-36664.

64. Viegas CSB, Cavaco S, Neves PL, Ferreira A, Joao A, et al. (2009) Gla-rich protein (GRP) is a novel vitamin $\mathrm{K}$ dependent protein present in serum and accumulated at sites of pathological calcifications. Am J Pathol 175: 2288-2298.

65. Rafael MS, Cavaco S, Viegas CS, Santos S, Ramos A, et al. (2014) Insights into the association of Gla-rich protein and osteoarthritis, novel splice variants and $\hat{\mathrm{I}}^{3}$-carboxylation status. Mol Nutr Food Res 58: 1636-1646. 
Citation: Viegas CSB, Simes DC (2016) New Perspectives for the Nutritional Value of Vitamin K in Human Health. J Nutr Disorders Ther 6: 192. doi:10.4172/2161-0509.1000192

Page 5 of 5

66. Viegas CS, Rafael MS, Enriquez JL, Teixeira A, Vitorino R, et al. (2015) Gla-rich protein acts as a calcification inhibitor in the human cardiovascular system. Arterioscler Thromb Vasc Biol 35: 399-408.

67. Cavaco S, Viegas CS, Rafael MS, Ramos A, et al. (2016) Gla-rich protein is involved in the cross-talk between calcification and inflammation in osteoarthritis. Cell Mol Life Sci 73: 1051-1065.

68. Sperling R, Furie BC, Blumenstein M, Keyt B, Furie B (1978) Metal binding properties of gamma-carboxyglutamic acid. Implications for the vitamin K-dependent blood coagulation proteins. J Biol Chem 253: 3898-3906.

69. Murshed M, Schinke T, McKee MD, Karsenty G (2004) Extracellular matrix mineralization is regulated locally; different roles of two glacontaining proteins. J Cell Biol 165: 625-630. 